\title{
Emoções nas Ruas: Uso do "Test of Emotions Comprehension" em Crianças em Situação de Trabalho na Rua
}

\author{
Emotions on the Streets: Application of the Test of Emotions Comprehension \\ in Children Working on the Streets
}

\author{
Carla Alexandra da Silva Moita Minervino*,a, Maria da Graça Bompastor Borges Dias ${ }^{b}$, Natércia \\ Janine Dantas da Silveira ${ }^{a}, \&$ Antonio Roazzi $^{b}$ \\ ${ }^{a}$ Universidade Federal da Paraíba \& ${ }^{b}$ Universidade Federal de Pernambuco
}

\begin{abstract}
Resumo
O presente estudo teve por objetivo analisar o desenvolvimento da competência emocional em crianças encontradas realizando trabalho informal nas ruas de duas cidades do nordeste brasileiro. Foram entrevistadas sessenta e sete crianças, com idades compreendidas entre quatro e doze anos, de ambos os sexos. O instrumento utilizado foi o Teste de Compreensão das Emoções. A coleta realizou-se no espaço da rua. Os resultados revelaram que apesar das crianças mais velhas terem obtido resultados melhores do que as mais novas estas diferenças não foram significativas. Foi observado que o Teste de Compreensão das Emoções foi bem aceito pelas crianças investigadas e revela-se como um instrumento de fácil utilização e que atinge os seus objetivos, no entanto sugerem-se novas investigações em contextos como o investigado. Palavras-chave: Crianças em situação de trabalho na rua; Emoções; TEC.
\end{abstract}

\begin{abstract}
The goal of the current research was to examine the development of nine components of emotions. For this purpose, 67 children, between 4 and 12 years old, who were found informally working on the streets of two cities in the Northeast of Brazil were interviewed. Children were given a version of the Test of Emotion Comprehension (TEC) to assess their understanding of nine different aspects of emotions. The collection of data happened in the space of the street. The results revealed that the oldest children obtained better results than the youngest ones. But these differences were not significant. It was observed that the TEC was well accepted by the investigated children and it is revealed as an instrument of easy use that reaches its objectives.

Keywords: Children in street situation; Emotions; TEC.
\end{abstract}

O cenário da rua configura-se para algumas pessoas, como um local de passagem, para outras, meio de diversão, compras, passeios, trabalhos. Entretanto, o cenário é utilizado para uma gama de fazeres, por uma multiplicidade de atores sociais em diferentes contextos, tempos e espaços.

Existe uma parcela da sociedade, que sobrevive ou até mesmo mora nas ruas, é fato que a busca pela sobrevivência vem assumindo dimensões alarmantes, conforme o Fundo das Nações Unidas para a Infância ([UNICEF], 2000) são 100 milhões de pessoas em todo o mundo que estão à margem da sociedade, desenvolvendo as mais variadas atividades.

De fato, o aumento gradativo desse fenômeno demonstra dramaticamente, que as garantias prometidas pela constituição não saíram do papel e que o direito de se vi-

\footnotetext{
* Endereço para correspondência: Universidade Federal da Paraíba, Centro de Educação, Cidade Universitária, João Pessoa, PB, Brasil, CEP 58032-100. E-mail: carlamoita@globo.com
}

ver decentemente ainda é proibitivo para muita gente. Pode-se afirmar que são de sujeitos que estão sendo usurpados de seus direitos básicos: saúde, alimentação, educação, convivência familiar, lazer, viver a infância, sem qualquer forma de negligência, violência e exploração. Não estão sendo atendidos pela sociedade, nem muito menos pelo Estado, a própria constituição está sendo violada, a UNICEF (2000) destaca que aproximadamente $75 \%$ dessa população é constituída por crianças.

As crianças realizam as mais diversas atividades nas ruas, vivenciando um sofrimento nos seus corpos, decorrentes de esforços físicos e desgastes. Segundo Alberto (2002) as implicações poderão se constituir em aspectos somatizados que implicarão diretamente no desenvolvimento, podendo aparecer sob diversas formas: irritabilidade, agressividade, dificuldade de relacionamento.

A rua também se constitui como um cenário fomentador de um mosaico de emoções, tais como: tristeza, felicidade, medo, euforia, angústia. São emoções expressas pelas crianças, em olhares que transcendem o cenário 
em que se encontram e se implicam nos sentimentos aparentemente não vistos, mas explicitamente expressos.

Segundo Paludo (2002) o conhecimento e a compreensão das emoções expressas em situação de rua propicia a obtenção de informações que podem subsidiar ações de prevenção e intervenção.

Dessa forma, o campo de investigação sobre o desenvolvimento e aplicabilidade da competência emocional, que caracteriza-se pelo reconhecimento, compreensão e respostas emocionais, está crescendo cada vez mais nos últimos anos, tanto no cenário internacional como em nosso contexto, principalmente com a emergência de diversas pesquisas transculturais. A crescente complexidade das demandas sociais em nossa sociedade, tanto a nível pessoal como profissional, fazem com que haja um aumento no interesse para o estudo desta competência, em decorrência das implicações que tal construto desempenha em outras competências da criança, na teoria da mente, nas habilidades verbais e nas cognitivas em geral, como também nos diferentes âmbitos aplicativos: familiar, escolar e o mais abrangente social.

De acordo com Paludo (2002) a competência emocional auxilia na distinção das características morais em contextos específicos, motivam o comportamento e revelam valores. Nas últimas décadas (Frijda \& Manstead, 2000; Harris, 1989; Harris, Rosnay, \& Pons, 2005; Saarni, Mumme, \& Campos, 1998) as pesquisas demonstraram que a competência emocional sofre alterações de acordo com a idade e revelam pelo menos nove componentes distintos da compreensão da emoção (do simples reconhecimento das emoções na base de expressões faciais às emoções que envolvem os julgamentos morais).

Pesquisas recentes sobre o construto da competência emocional, têm demonstrado que esta competência se desenvolve entre os 3 e 11 anos e se manifesta nas capacidades de reconhecer expressões faciais, de compreender a natureza, as causas e a possibilidade de controle das emoções (Roazzi, Dias, Minervino, Roazzi, \& Pons, 2008).

Neste sentido desde 2004, Pons, Harris e Rosnay vêm investigando um paradigma de pesquisa que tem possibilitado estudar de forma mais precisa a compreensão das emoções em crianças, considerando simultaneamente nove componentes que, em função do nível de desenvolvimento, podem ser agrupadas em três fases hierárquicas: uma fase externa (3-6 anos) que envolve a possibilidade de identificar expressões faciais que indicam uma emoção, causadas por fatores externos e a capacidade de recordar uma lembrança passada que possa causar uma emoção, uma fase mental (5-9 anos) que inclui a capacidade de compreender que as emoções são resultantes de crenças e desejos individuais, envolvendo a diferenciação entre estados reais e aparentes, o que não pode ser baseado em simples análise das expressões faciais e comportamentais, mas, sobretudo, na compreensão de representações mentais, e uma fase reflexiva (8-12 anos) que inclui a possibilidade de identificar que uma pessoa pode sentir mais do que uma emoção, inclui as emoções morais, tais como culpa e o controle mental das emoções.

Para a avaliação da competência emocional foram desenvolvidos diversos tipos de instrumentos de medida, tais como o desempenho de papéis em situações planejadas envolvendo por exemplo personagens inanimados: desenhos representando personagens das histórias ou objetos, fantoches ou animais de pelúcia (Baron-Cohen, Leslie, \& Frith, 1985; Hadwin \& Perner, 1991; Harris, Johnson, Hutton, Andrew, \& Cooke, 1989; Wimmer \& Perner, 1983), as medidas baseadas em entrevistas, a observação de interações naturais das crianças com pessoas de seu ambiente e os instrumentos de reconhecimento de expressões faciais de emoções. Entretanto, estes instrumentos visam observar componentes particulares do construto, considerando esta lacuna tornou-se importante a elaboração de instrumentos que possam observar a competência emocional, considerando simultaneamente os nove componentes.

Baseados na literatura experimental Pons, Harris e Rosnay propuseram o instrumento Test of Emotion Comprehension ([TEC], Pons \& Harris, 2000; Pons et al., 2004) que visa, portanto, analisar o desenvolvimento da competência emocional em crianças através da compreensão dos nove componentes das emoções: expressão facial de emoções, as causas situacionais externas de emoções, as relações entre desejos, crenças e emoções, o impacto de lembranças na emoção, os efeitos de distração, a diferença entre emoções verdadeiras e evidentes, possibilidade de experimentar emoções mistas, e a relação entre sensações culpa e o errado. As propriedades psicométricas do TEC foram observadas a partir das respostas de uma amostra de crianças inglesas sendo priorizada a análise de estrutura fatorial, da consistência interna do instrumento (alfa de Cronbach $=0,67$ ). Também foram conduzidas análises de teste-reteste com 3 meses (Pons, Harris, \& Doudin, 2002), e com13 meses, sendo controlados os efeitos de gênero (Pons, Lawson, Harris, \& Rosnay, 2003).

No entanto, destaca-se que a maior parte das pesquisas sobre o desenvolvimento da competência emocional tem sido conduzida com crianças que vivem na Europa e América do Norte, a exemplo das pesquisas realizadas com o TEC na Itália (Molina \& Di Chiacchio, 2008) e Inglaterra (Pons \& Harris, 2005; Rosnay, Pons, Harris, \& Morrell, 2004). Vários estudos incipientes vêm sendo conduzidos concomitantemente em outros contextos tais como estudos preliminares com crianças asiáticas (Tardiff \& Wellman, 2000) que revelam um modelo de desenvolvimento da compreensão das emoções semelhante aos encontrados na Europa, no que diz respeito aos componentes: compreensão entre aparência e realidade (Flavell, Zhang, Zou, Dong, \& Qi, 1983), distinção entre emoção verdadeira e expressa (Gardner, Harris, Ohmoto, \& Hamazaki, 1988; Joshi \& MacLean, 1994) e 
recordação da emoção (Harris, Guz, Lipian, \& Shu, 1985). $\mathrm{Na}$ América Latina foi realizado estudo com crianças de uma vila agropastoril no Peru (Tenenbaum, Visscher, Pon, \& Harris, 2004) que revelou semelhanças com as crianças britânicas no que diz respeito aos componentes: reconhecimento e regulação das emoções, o que sugere modelo semelhante na seqüência da compreensão emocional apesar da diferença radical no contexto cultural, em contraste com crianças de inglesas as crianças da aldeia peruana têm pouco acesso à educação formal, a pesquisa sugere que a instrução formal facilita a compreensão das emoções (Vinden, 2002), possivelmente devido as interações em sala de aula (Pons et al., 2002). Em relação ao componente referente compreensão de crenças, as crianças peruanas apresentaram um atraso em relação às crianças inglesas (Tenenbaum et al., 2004).

Em suma, observa-se a importância de investigações com crianças de diversos contextos e culturas. Tendo em vista a ausência de estudos no Brasil, utilizando o TEC, o presente estudo teve por objetivo analisar a competência emocional em crianças encontradas realizando trabalho informal nas ruas de duas capitais brasileiras, através da mesma metodologia do instrumento original, como forme será descrito no método, foi observado o conjunto dos componentes que avaliam a compreensão das emoções possibilitando desta forma de verificar empiricamente o perfil evolutivo das referidas crianças.

\section{Método}

\section{Participantes}

Participaram da pesquisa sessenta e sete crianças que estavam realizando algum tipo de trabalho na rua, com idades compreendidas entre quatro e doze anos, de ambos os sexos, em duas capitais do Nordeste Brasileiro.

Da amostra 56\% eram meninos e $44 \%$ meninas. As crianças foram distribuídas em dois grupos de acordo com a faixa etária: grupo $l$ (crianças mais novas) constituído por crianças entre 4 e 7 anos (3\%); grupo 2 (crianças mais velhas) foi composto crianças entre 8 e 12 anos (97\%).

As crianças realizavam as mais diversas atividades na rua, sendo caracterizados como trabalhadores precoces, consideram-se trabalho as atividades executadas por crianças, que possibilitava a própria sobrevivência ou a dos outros, abrange uma gama de fazeres realizado com ou não remuneração.

Os entrevistados realizavam uma verdadeira travessia nas ruas das cidades em uma luta pela sobrevivência, exercendo atividades como: vendedor (24\%), ajudante de feiras $(24 \%)$, doméstica $(12,5 \%)$, catador de lixo (6,5\%), babá (6\%), ajudante de mercearias $(6 \%)$, mecânico $(6 \%)$, pedreiro $(6 \%)$, prostitutas $(2,5 \%)$, Pedinte $(2,5 \%)$, lixador de moveis $(1 \%)$, servente $(1 \%)$, pintor (1\%), limpador de túmulos (1\%). Cabe mencionar a ocorrência de crianças com mais de uma atividade.

As atividades desenvolvidas exigem pouca ou nenhuma qualificação formal, embora requeiram certas habi- lidades cognitivas de cálculo e de planejamento em relação ao uso do dinheiro.

\section{Instrumentos}

Nesse estudo, foram utilizados dois instrumentos: uma entrevista semi-estruturada e o TEC (Test of Emotion Comprehension), cuja descrição encontra-se abaixo.

Roteiro para Entrevista. Com relação aos dados sócio-demográficos, foram coletados por meio de uma entrevista semi-estruturada, adaptada de um roteiro de entrevista de Paludo (2002). A entrevista contem questionamentos relacionados com a vida da criança e a capacidade da criança perceber dados relevantes de suas vivências, questiona-se, por exemplo: se a criança sabe informar a data de seu aniversário, como é o seu trabalho, onde e com quem vive, além de questionamentos sobre como é o dia-a-dia na rua (Anexo).

Test of Emotion Comprehension (TEC). O TEC possui, em sua versão original, nove fatores correspondentes aos componentes emocionais. Solicita-se da criança a atribuição de um estado emocional representado por uma expressão facial, adequada ao contexto referendado. Existe tanto uma versão para sujeitos do sexo masculino como uma versão para sujeitos do sexo feminino, e consiste em um livro de ilustrações em papel A4 com histórias em quadrinhos com um simples enredo na parte superior. Há um cenário apropriado, na parte inferior das páginas, em que existem quatro sequiências de emoções representadas por expressões faciais. O procedimento de aplicação, de um modo geral, é dividido em duas etapas. A primeira consiste em mostrar uma figura do cenário, enquanto o pesquisador lê uma história que acompanha cada ilustração sobre a pintura da parte superior do livro. Depois de escutá-las, a criança escolhe na parte inferior do livro em que estão inseridas, dentre quatro opções de respostas em formato de figuras, a principal emoção expressa nas faces (Tenenbaum et al., 2004).

Assim, inicialmente se lê uma breve história enquanto a criança observa esta figura na parte superior da folha (cujo protagonista tem o rosto em branco, sem qualquer expressão, portanto). Em seguida solicita-se da criança de indicar a expressão facial considerada mais adequada ao contexto da história. Para isso na parte inferior de cada folha estão apresentadas quatro possíveis consequiências emocionais representadas por expressões faciais. As respostas das crianças são não-verbais, tendo em vista que estudos transculturais estabelecem que as expressões faciais relacionadas às situações são similares entre diversas culturas. Ekman (1975) concluiu em seus estudos que os povos em geral demonstram as emoções através das mesmas expressões faciais, mas quando expressam e com quem expressam é que varia em cada cultura.

O TEC está dividido em blocos de histórias em ordem pré-estabelecida. O instrumento apresenta os seguintes nove componentes:

Componente 1. O reconhecimento das emoções, baseado nas expressões faciais; esse primeiro componente 
envolve o reconhecimento de emoções como: tristeza, felicidade, raiva, normal (sem alteração de emoções), medo. Abrange, portanto, cinco itens e tem por objetivo observar o reconhecimento de expressões faciais das emoções. O pesquisador mostra as figuras e questiona: "Vamos olhar para estas quatro figuras. Você poderia apontar a pessoa que esta se sentindo: feliz" (Figura 1). Conforme o critério de análise atribuiu-se um ponto para no mínimo três itens corretos, em um total de cinco.
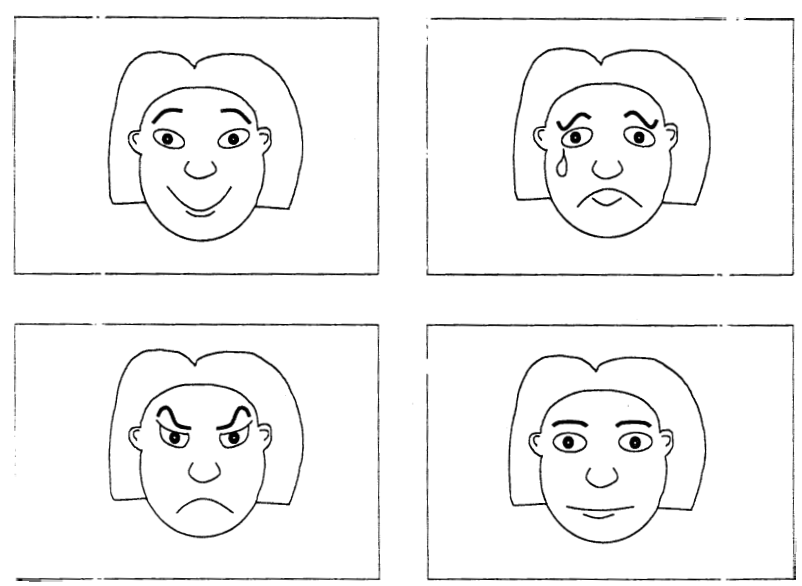

Figura 1. Primeira prancha para reconhecimento de emoções básicas constituinte do componente do TEC (Pons \&Harris, 2000)

Componente 2. Compreensão das causas externas das emoções; este componente abrange o reconhecimento das emoções ocasionadas por situações externas, a saber: tristeza, felicidade, raiva, normal, medo. Neste componente o pesquisador conta uma pequena história e depois questiona a criança sobre a emoção que representa o que o personagem da história deverá estar sentindo, por exemplo: "Este menino/a está olhando para sua tartaruga que acabou de morrer. Como é que este menino/a esta se sentindo? Ele/ela está feliz, triste, com raiva ou bem?". São cinco histórias. Sendo assim, os critérios de correção seguem os do primeiro componente, considerando cinco itens.

Componente 3. Compreensão do desejo despertado; $\mathrm{O}$ terceiro componente aponta para o reconhecimento dos desejos entre as crianças, na perspectiva em que duas pessoas vivenciam desejos diferentes, envolvendo quatro cartoons: feliz/ triste; triste/feliz. O pesquisador conta a história de duas crianças que possuem sede, sendo que uma delas gosta de refrigerante e a outra não, em seguida o pesquisador pede para que a criança abra uma caixa que estava até então fechada onde existe um refrigerante e questiona: "Como o menino 1 esta se sentindo quando vê o refrigerante?" É considerada correta a resposta adequada para a expressão emocional de cada criança da história.

Componente 4. Compreensão das emoções baseadas em crenças; atribuições de uma emoção para um coelho que está comendo uma cenoura sem compreender o que tem escondido na caixa.

Componente 5. Compreensão da influência da lembrança em circunstâncias de avaliação de estados emocionais; atribuição de uma emoção para uma característica que lembra a perda de um objeto precioso.

Componente 6. Compreensão das possibilidades de controlar as experiências emocionais; atribuição de uma estratégia psicológica que eles pensam para pararem de ficar tristes.

Componente 7. Compreensão da possibilidade de esconder um estado emocional; atribuição de uma emoção para uma situação que pode provocar tanto sentimentos negativos quanto positivos.

Componente 8. Compreensão de confusão de emoções.

Componente 9. Compreensão de expressões morais; atribuição de uma emoção que algo está errado de acordo com as normas impostas pela mãe, por exemplo. Para a análise, um ponto é atribuído para cada componente respondido corretamente.

No total cada criança poderá obter no máximo 9 pontos e no mínimo 0 .

\section{Procedimentos}

A coleta dos dados foi realizada em duas cidades do nordeste brasileiro, no ambiente de rua, as crianças em sua grande maioria (90\%) encontravam-se em grupos, sem a presença de um adulto cuidador, entretanto foram entrevistadas individualmente. Para tanto, foi utilizado o procedimento da inserção ecológica.

Conforme Cecconello e Koller (2003) a realização da inserção ecológica é de suma importância, na medida em que os pesquisadores precisam tornar-se parte do ambiente para adquirir a condição de inserida ecologicamente no espaço da pesquisa dos participantes, o que pode possibilitar a construção de espaços de fala, reflexões e aprendizagens, na medida em que o pesquisador torna-se presença constante no ambiente.

As crianças foram entrevistas seguindo o roteiro e em seguida foi aplicado o TEC (Test of Emotion Comprehension).

Após a coleta dos dados as respostas foram anotadas e analisadas estatisticamente, para tanto foram utilizados o teste One-way Anova e o teste Qui-quadrado. O Anova foi utilizado para análise da compreensão das emoções em relação com a idade,o Qui-quadrado foi utilizado para análise dos componentes de forma geral.

\section{Considerações Éticas}

As questões éticas envolvendo seres humanos têm sido amplamente discutidas, a resolução $\mathrm{n}^{\circ} 196$ aponta que os estudos devem atender às exigências éticas e científicas, caracterizados pela não exposição dos participantes aos riscos e devem considerar a relevância social da pesquisa. Destaque para a existência de resolução $\mathrm{N}^{\circ} 116$ referente às pesquisas envolvendo populações conside- 
radas de risco, que não exigem o consentimento informado de pais, caso não possuam contado sistemático com seus filhos, guardiões legais que não tenham condições cognitivas para avaliar as consequiências da participação de crianças na pesquisa e, ainda, pais ou guardiões que tenham abusados, negligenciado ou sido convenientes com abusos de seus filhos.

Desta forma, este estudo foi norteado, sobretudo, pelos princípios éticos comprometendo-se a seguir as resoluções supracitadas, principalmente, em relação às situações que envolvem as crianças em situação de risco, garantindo sigilo e proteção dos participantes; ética compreendida, neste espaço, enquanto compromisso com o outro, tendo como intuito ainda, que as informações coletadas sejam utilizadas como uma forma de subsidiar a sociedade e os poderes públicos na resolução desta problemática. O projeto fora submetido e aprovado pelo Comitê de Ética da Universidade Estadual da Paraíba cadastrado no (CNS/SISNEP) sob o número 2455.0.000.133-07.

\section{Resultados}

Os resultados são apresentados em três partes. Primeiramente serão descritos os dados encontrados a partir da entrevista semi-estruturada, o que permitirá a visualização do perfil das crianças investigadas. Em seguida são apresentadas as pontuações globais no TEC e a relação com a idade. No terceiro momento são apresentados os resultados das crianças em cada componente do TEC.

A entrevista foi realizada individualmente, em um tempo médio de 20 minutos. Os resultados revelaram que a totalidade dos entrevistados mora em bairros periféricos, alguns, porém dormiam nas ruas das cidades. Quanto as suas famílias são geralmente bastante extensas, possuindo em média oito membros, sendo não-nucleares, com um poder aquisitivo muito baixo, em média menor que um salário mínimo.

Em relação à paternidade, grande parte dos entrevistados não possui a figura paterna, ou, muitas vezes, o desconhecem. Os que possuem pai relataram que os pais realizam os mais diversos tipos de trabalho, como: pedreiro, sapateiro, feirante, marceneiro, desempregado, vendedor, vigilante, carroceiro, catador de lixo, policial, lavador de carro, ajudante de fábrica, moto-táxi e agricultor.

Quanto à figura materna, algumas crianças, também, falaram sobre a perda de suas mães, e em outros casos: da situação de desemprego em que se encontravam. Acrescentando que as mães, em sua maioria, assumem o papel de cuidadoras dos filhos. As profissões mais freqüentes foram: babá, doméstica, lavadeira, cozinheira, faxineira, "carroceira" (sic) e vendedora.

No que remete a escolaridade, $100 \%$ dos entrevistados responderam que freqüentam, ou freqüentaram a escola. Entretanto, constatou-se que a ida a escola, estava atrelada ao recebimento de bolsas, à participação em pro- gramas sociais, que exigem uma freqüência nessas instituições. Além disso, alguns os atores sociais relataram possuir uma defasagem escolar de, em média, de três anos (conforme relato das crianças).

Após terem sido entrevistadas, cada criança respondeu ao TEC.

$\mathrm{O}$ primeiro questionamento que se pretendia responder com a utilização do TEC era se as crianças mais velhas evidenciavam uma melhor compreensão das expressões emocionais do que as crianças mais jovens, a exemplo do que foi realizado no Peru e na Inglaterra. Assim, para analisar esta questão foi utilizada uma ANOVA, com a idade (mais velhas e mais novas) e com o gênero (meninos e meninas), a variável dependente foi o escore total obtido no TEC. Não foi verificado efeitos principais de gênero nem significância de interação, no entanto era esperado o efeito da idade, fato que não ocorreu $(F(3)=1,04, p=0,381)$. As crianças mais velhas obtiveram média de acertos $=4,53(D P=1,60)$ e as mais novas obtiveram média de acertos $=4(D P=1,56)$. Ao comparar os resultados da presente amostra com os resultados das crianças da vila agropecuária do Peru $(n=$ 39) com idade entre 4 e 7 anos (Tenenbaum et al., 2004) e com as crianças inglesas $(n=100)$ de idade entre 3 e 11 anos, sem histórico de repetência escolar, de classe baixa e média. (Pons et al., 2004) observa-se que as crianças peruanas mais velhas tiveram média de acertos $=3,57$ $(D P=1,57)$ e as crianças mais velhas inglesas obtiveram média igual $=7,93(D P=1,10)$, nota-se que as crianças inglesas tiveram média consideravelmente maior do que as demais amostras. No entanto para efeitos de comparação seria necessário maior correspondência entre os três grupos: brasileira, peruanas e inglesas. Porém notase um padrão de resposta semelhante quando observa-se o grupo de crianças mais novas brasileiras com o grupo de crianças mais velhas peruanas (mesma idade).

Passa-se a análise por componente do TEC.

Os componentes são apresentados conforme a ordem no instrumento (TEC). Os resultados consideram o grupo total das crianças investigadas (67 crianças).

Na Tabela 1 pode ser verificada a distribuição dos componentes do TEC em função dos grupos de idades, demonstrando os níveis de significância de acordo com as respostas das crianças.

Componente 1. Reconhecimento das emoções, baseado nas expressões faciais. Em relação ao componente 1 constatou-se que $77,5 \%$ das crianças investigadas reconheceram três ou mais expressões das emoções solicitadas, e $22,5 \%$ não conseguiram reconhecer adequadamente.

Componente 2. Compreensão das causas externas das emoções constatou-se que a maior parte das crianças $(80,5 \%)$ reconheceu a emoção para cada situação, enquanto que $19,5 \%$ não reconheceram.

Componente 3. Compreensão do desejo despertado. Verificou-se que $64 \%$ reconheceram corretamente a expressão emocional para cada um dos personagens. 
Minervino, C. A. S. M., Dias, M. G. B. B., Silveira, N. J. D. \& Roazzi, A. (2010). Emoções nas Ruas: Uso do "Test of Emotions Comprehension" em Crianças em Situação de Trabalho na Rua.

Tabela 1

Reconhecimento das Emoções por Componente do TEC e por Idade, Freqüência, Significância (p). Teste Quiquadrado

\begin{tabular}{lcccc}
\hline $\begin{array}{l}\text { Reconhecimento } \\
\text { das emoções }\end{array}$ & \multicolumn{4}{c}{$\begin{array}{l}\text { Grupo que a criança pertence } \\
\text { de acordo com a variável idade }\end{array}$} \\
\cline { 2 - 5 } & $4-7$ & $8-12$ & $4-12$ anos & $\mathrm{p}$ \\
\hline Componente I & 2 & 50 & 52 & 0,32 \\
Componente II & 1 & 53 & 54 & 0,02 \\
Componente III & 1 & 42 & 43 & 0,50 \\
Componente IV & 1 & 31 & 32 & 0,44 \\
Componente V & 1 & 31 & 32 & 0,04 \\
Componente VI & 0 & 28 & 28 & 0,67 \\
Componente VII & 0 & 37 & 37 & 0,20 \\
Componente VIII & 0 & 13 & 13 & 0,81 \\
Componente IX & 0 & 22 & 22 & 0,79 \\
\hline
\end{tabular}

Componente 4. Compreensão das emoções baseadas em crenças. Com relação ao quarto componente, que diz respeito às crenças, $52 \%$ dos entrevistados não obtiveram pontuação no item, porém $48 \%$ acertaram-no. Cabe destacar que, a partir desse item, os componentes são constituídos e pontuados com um ponto por acerto.

Componente 5. Compreensão da influência da lembrança em circunstâncias de avaliação de estados emocionais. Quanto ao quinto componente, recordação de emoções passadas, $52 \%$ das crianças demonstrou não recordá-las, enquanto que $48 \%$ dos entrevistados parecem ter do domínio desse componente.

Componente 6. Compreensão das possibilidades de controlar as experiências emocionais. No que tange ao sexto componente, relacionado à regulação das emoções, a maior parte dos entrevistados (58\%) demonstraram não possuir o controle de suas emoções.

Componente 7. Compreensão da possibilidade de esconder um estado emocional. Com relação ao sétimo componente, relacionado à aparência e realidade, verificou-se que a maior parte dos entrevistados (55\%) faz a distinção entre aparência e da realidade.

Componente 8. Compreensão de confusão de emoções. $\mathrm{O}$ oitavo componente remete-se as emoções conflitivas, obteve-se, assim, que a maior parte das crianças entrevistadas não identificou corretamente $(n=45 ; 80,5 \%$ da amostra total).

Componente 9. Compreensão de expressões morais. Em relação às expressões das emoções morais, nono componente, quase totalidade das crianças (97\%), revelou a não compreensão das expressões morais.

Nota-se, ao se comparar com as amostras de crianças peruanas e inglesas, que existe similaridade das respostas das crianças investigadas, em relação aos primeiros componentes, quando comparada com as crianças inglesas, porém a partir do componente 3 nota-se maior similaridade com as crianças peruanas (Tabela 2).

Tabela 2

$\%$ de Respostas Corretas por cada Componente para a Amostra Inglesa $(N=100)$, Peruana $(N=39)$ e Brasileira $(N=67)$

\begin{tabular}{lccccccccc}
\hline & I & II & III & IV & V & VI & VII & VIII & IX \\
\hline Inglaterra & 84 & 79 & 66 & 68 & 81 & 39 & 59 & 39 & 40 \\
Brasil & 77 & 80 & 64 & 47 & 47 & 41 & 55 & 19 & 2 \\
Peru & 49 & 44 & 26 & 46 & 23 & 15 & 41 & 33 & 23 \\
\hline
\end{tabular}

\section{Discussão}

O presente estudo visou apresentar os resultados da análise da competência emocional em crianças encontradas realizando trabalho informal nas ruas. Os resultados mostram que não houve diferença entre o desempenho de crianças mais velhas e mais novas na compreensão global das emoções, analisada através do TEC. Esta inexistência de diferença chama a atenção para a necessidade de maiores estudos sobre a adaptação do TEC em culturas diferenciadas.

Os estudos sobre TEC sugerem que a diferença de idade no desempenho das crianças caracteriza o TEC como uma medida adequada para as exigências cognitivas impostas pelos componentes específicos de compreensão das emoções (Pons et al., 2004), no entanto os dados da presente pesquisa sugerem a necessidade de maiores investigações em crianças em situações sociais consideradas de risco, sugere-se pesquisas com amostras maiores e que possam considerar a variável idade de forma homogênea entre os grupos, fato que não foi possível neste estudo.

No que remete ao componente das emoções despertadas por causas externas e por desejos, as crianças analisadas mostraram compreender melhor as emoções provocadas por causas externas em relação às emoções provocadas por desejo despertado, assim como nos estudos Tenenbaum et al. (2004) no qual as crianças peruanas mais velhas exibiram uma maior compreensão das causas externas das emoções e compreensão das emoções do que os desejos das pessoas diferentes provocando emoções diferentes. 
Com relação às emoções que envolvem crenças, a maior parte das crianças (52\%) desse estudo demonstrar não compreender as emoções. O mesmo ocorreu nos estudos de Tenenbaum et al. (2004) no qual as crianças peruanas não compreenderam esse tipo de emoção, tal compreensão aparece significativamente nos estudos de Pons et al. (2004) com as crianças inglesas, no qual as crianças com sete anos de idade foram capazes de compreender com clareza as emoções que envolve crenças, desejos e a possibilidade de esconder a emoção.

Já as crianças inglesas de 9 a 11 anos foram capazes de compreender claramente a natureza mista das emoções, a possibilidade de regular as emoções através da cognição, e a influência da moral. O que não foi observado nesse estudo, pois a maioria das crianças apresentaram dificuldades em compreender a regulação das emoções, $80,7 \%$ não compreendeu as emoções mistas e $97 \%$ as emoções morais.

Ao comparar as crianças desse estudo, com as inglesas $\mathrm{e}$ as peruanas percebe-se que a cultura e o contexto nos quais as crianças estão inseridas, assim como as experiências afetivas e sociomorais, o desenvolvimento e as limitações cognitivas afetam a compreensão e o entendimento das emoções, o que aponta para a necessidade da continuidade das pesquisas com o TEC em outros contextos e culturas.

\section{Referências}

Alberto, M. F. (2002). As dimensões subjetivas do trabalho precoce de meninos e meninas em condição de rua em João Pessoa-PB. Tese de Doutorado não-publicada, Programa de Pós-Graduação em Sociologia, Universidade Federal de Pernambuco, Recife, PE.

Baron-Cohen, S., Leslie, A. M., \& Frith, U. (1985). Does the autistic child have a "Theory of Mind"? Cognition, 21, 37-46.

Cecconello, A. M., \& Koller, S. (2003). Avaliação da competência social em crianças em situação de risco. Psico - USF, 8, 1-9.

Ekman, P. (1975). Face muscles talk every language. Psychology Today, 9, 35-39.

Flavell, J. H., Zhang, X., Zou, H., Dong, H., \& Qi, S. (1983). A comparison between the development of the appearancereality distinction in the people's Republic of China and the United States. Cognitive Psychology, 15, 459-466.

Frijda, N. H., \& Manstead, A. S. R. (2000). Emotions and beliefs: How feelings influence thoughts. Cambridge, MA: Cambridge University Press.

Fundo das Nações Unidas para a Infância. (2000). Situação mundial da infância. Brasília, DF: Autor.

Gardner, D., Harris, P. L., Ohmoto, M., \& Hamazaki, T. (1988). Japanese children's understanding of the distinction between real and apparent emotions. International Journal of Behavioral Development, 11, 203-218.

Hadwin, J., \& Perner, J. (1991). Pleased and surprised: Children's cognitive theory of emotion. British Journal of Developmental Psychology, 9, 215-234.

Harris, P. L. (1989). Children and emotion: The development of psychological understanding. Oxford, UK: Blackwell.
Harris, P. L., Guz, G. R., Lipian, M. S., \& Man-Shu, Z. (1985). Insight into the time course of emotion among Western and Chinese children. Child Development, 56, 972-988.

Harris, P. L., Rosnay, M., \& Pons, F. (2005). Language and children's understanding of mental states. Current Directions in Psychological Science, 14(1), 69-73.

Harris, P. L., Johnson, C. N., Hutton, D., Andrews, G., \& Cooke, T. (1989). Young Children's Theory of mind and emotion. Cognition and Emotion, 3, 379-400.

Joshi, M., \& MacLean, M. (1994). Indian and English children's understanding of the distinction between real and apparent emotion. Child Development, 65, 1372-1384.

Molina, P., \& Di Chiacchio, C. (2008). La Standardizzazine Italiana. In O. Albanese \& P. Molina (Eds.), Lo sviluppo della comprensione delle emozioni e la sua valutazione (pp. 65-105). Milano, Italy: Unicopli.

Paludo, S. S. (2002). A expressão das emoções morais de crianças em situação de rua. Dissertação de Mestrado nãopublicada, Programa de Pós-Graduação em Psicologia do Desenvolvimento, Universidade Federal do Rio Grande do Sul, Porto Alegre, RS.

Pons, F., \& Harris, P. L. (2000). TEC (Test of Emotion Comprehension). Oxford, UK: Oxford University Press.

Pons, F., \& Harris, P. (2005). Longitudinal change and longitudinal stability of individual differences in children's emotion understanding. Cognition and Emotion, 19(8), 11581174.

Pons, F., Harris, P. L., \& Doudin, P.-A. (2002). Teaching emotion understanding. European Journal of Psychology of Education, 17, 293-304.

Pons, F., Harris, P. L., \& Rosnay, M. (2004). Emotional comprehension between 3 and 11 years: Developmental periods and hierarchical organization. European Journal of Developmental Psychology, 1(2), 127-152.

Pons, F., Lawson, J., Harris, P. L., \& Rosnay, M. (2003). Individual differences in children's emotion understanding: Effects of age and language. Scandinavian Journal of Psychology, 44, 345-351.

Roazzi, A., Dias, M. G. B. B., Minervino, C. M. M., Roazzi, M., \& Pons, F. (2008). Compreensão das emoções em crianças: Estudo transcultural sobre a validação do Teste de Compreensão da Emoção TEC (Test of Emotion Comprehension). Actas da XIII Conferência Internacional de Avaliação Psicológica. 13, 213-233.

Rosnay, M., Pons, F., Harris, P., \& Morrell, J. (2004). A lag between understanding false belief and emotion attribution in young children: Relationships with linguistic ability and mothers' mental-state language. British Journal of Developmental Psychology, 22, 197-218.

Saarni, C., Mumme, D. L., \& Campos, J. (1998). Emotional development: Action, communication, and understanding. In W. Damon (Series Ed.) \& N. Eisenberg (Vol. Ed.), Handbook of Child Psychology: Vol. 3. Social, emotional, and personality development ( $5^{\text {nd }}$ ed., pp. 237-309). New York: Wiley.

Tardiff, T., \& Wellman, H. M. (2000). Acquisition of mental state language in Mandarin and Cantonese-speaking children. Developmental Psychology, 36, 25-43.

Tenenbaum, H., Visscher, P., Pons, F., \& Harris, P. L. (2004). Emotion understanding in Quechua children from an agropastoralist village. International Journal of Behavioral Development, 28(5), 471-478. 
Minervino, C. A. S. M., Dias, M. G. B. B., Silveira, N. J. D. \& Roazzi, A. (2010). Emoções nas Ruas: Uso do "Test of Emotions Comprehension" em Crianças em Situação de Trabalho na Rua.

Vinden, P. G. (2002). Understanding minds and evidence for belief: A study of Mofu children in Cameroon. International Journal of Behavioral Development, 26, 445-452.

Wimmer, H., \& Perner, J. (1983). Beliefs about beliefs: Representation and constraining function of wrong beliefs in young children's understanding of deception. Cognition,

\section{Anexo}

\section{Questionário Sócio-demográfico}

(Adaptado do Roteiro de Paludo, 2002)

Sexo: $\square$ masculino $\square$ feminino

Idade: A criança sabe informar a data do aniversário? $\operatorname{sim} \square$

não

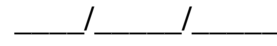

Freqüenta a escola? $\square \operatorname{sim} \square$ não

Sabe ler? $\square \operatorname{sim} \square$ não

Sabe escrever? $\square$ sim $\square$ não

Caso a criança não esteja freqüentando a escola no presente momento, perguntar:

Foi na escola? $\square \operatorname{sim} \square$ não

Por quanto tempo?

Até que série?

Por que saiu da escola?

Trabalha: $\square \operatorname{sim} \square$ não

Em que?

Como é seu trabalho?

Ganha dinheiro na rua? $\square \operatorname{sim} \square$ não

Como?

Onde mora?

Com quem vive?

Quem é a sua família?

Mantém contato com a família? $\square$ sim $\square$ não

Quando foi em casa pela última vez?

Profissão do pai:

Profissão da mãe:

1. Como é a vida na rua?

2. O que você gosta da rua?

3. O que você utiliza para fazer o que gosta na rua?

4. O que você não gosta da rua?

5. O que você utiliza para fazer o que você não gosta na rua? 